\title{
Recurrence of a Left Atrial Myxoma
}

JOSEPH A. WALTON, Jr., MD

DONALD R. KAHN, MD

PARK W. WILLIS, III, MD, FACC

Ann Arbor, Michigan
From the Division of Cardiology (Heart Station), Department of Internal Medicine and the Section of Thoracic Surgery, Department of Surgery, University of Michi. gan Medical School, Ann Arbor, Mich. Manuscript received April 27, 1970; revised manuscript received June 1, 1971, accepted June 22, 1971.

Address for reprints: Joseph A. Walton, Jr., MD, Heart Station, University Hospital, Ann Arbor, Mich. 48104.
A fatal recurrence of a left atrial myxoma was observed despite resection of the original tumor complete with its stalk and a portion of atrial septum. The evidence suggests that this recurrent tumor developed from "pre-tumor" cells in the region of the fossa ovalis. The rate of growth of the second tumor was faster than would have been predicted. Clinical manifestations were similar to those with the initial tumor. Wide excision of the atrial septum with the stalk of such tumors should offer the best chance for operative cure, but prolonged postoperative observation is important if signs of recurrence are to be detected at a time when operative removal can be carried out with minimal risk to the patient.

Since the first reports of successful excision of a left atrial myxoma in $1955,,^{1.2}$ this has been considered a curable form of heart disease. Recurrences are said to be unlikely after simple excision with or without electrocauterization of the site of excision. ${ }^{3}$ Experience with a patient in whom a left atrial myxoma recurred after simple excision with electrocauterization of the site led to emphasis on the importance of excision of the stalk and the adjacent atrial septum. ${ }^{4}$ However, recurrence of an atrial myxoma 6 years after this procedure was recently reported. ${ }^{5}$ Greenwood $^{6}$ pointed out that the long-term course after operative treatment is not known, but it is probably significant that recurrences have not been reported with any frequency. This study reports the death of a patient due to recurrence of a left atrial myxoma after excision of the original tumor, its stalk and an ample cuff of the atrial septum.

\section{Case History}

\section{University Hospital Admission 1}

A 49 year old white married woman was admitted on January 30 , 1965 complaining of "smothering spells" for 8 months, each spell lasting 2 to 3 minutes and associated with rapid, regular palpitations. She had also noted ankle edema, dyspnea on exertion and paroxysmal nocturnal dyspnea. There was no history of rheumatic fever, hypertension, heart murmur, peripheral embolism, venous thrombosis or pulmonary embolism.

Blood pressure was $80 / 62 \mathrm{~mm} \mathrm{Ig}$, pulse was $120 / \mathrm{min}$ with a regular rhythm, and temperature was $97.2 \mathrm{~F}$. There was pallor, slight cyanosis and respiratory distress. The neck veins were distended in the $30^{\circ}$ sitting position, and there were prominent $\mathrm{V}$ waves. The lungs were clear. There was a left parasternal lift; the apical impulse was just outside the mid-clavicular line in the fifth left intercostal space; the first sound was loud at the apex, and the pulmonary component of the second heart sound was louder than the aortic component. A soft, early diastolic extra sound not typical of a mitral opening snap was 
TABLE I

\section{Pressures Recorded During Cardiac Catheterization}

\begin{tabular}{lcc}
\hline & \multicolumn{2}{c}{ Pressures (mm Hg) } \\
\hline \multicolumn{1}{c}{ Location } & $\begin{array}{c}\text { Initial Tumor } \\
(2 / 8 / 65)\end{array}$ & $\begin{array}{c}\text { Recurrent Tumor } \\
(12 / 15 / 66)\end{array}$ \\
\hline Right atrium & *A waves $10 ;$ & A waves $26 ;$ \\
& V waves $5 ;$ & V waves 24; \\
& mean 7 & mean 19 \\
Right ventricle & $85 / 0-6$ & $90 / 3-20$ \\
Pulmonary artery & $85 / 32$ & $90 / 40$ \\
Right pulmonary arterial wedge & A waves $0 ;$ & A waves $36 ;$ \\
& V waves $40 ;$ & V waves 39; \\
Left ventricle & mean 25 & mean 30 \\
Ascending aorta & $82 / 0-8$ & $\cdots$ \\
\hline
\end{tabular}

* Recorded before onset of atrial fibrillation.

heard at the apex. A grade 2/6 holosystolic murmur and a grade $1 / 6$ presystolic rumbling murmur were heard at the apex. The liver was palpable $6 \mathrm{~cm}$ below the right costal margin. There was no clubbing. There was $1+$ ankle edema.

The hematocrit was 35 percent, white blood cell count $13,800 / \mathrm{mm}^{3}$ with 84 percent polymorphonuclear leukocytes, 13 percent lymphocytes and 3 percent monocytes. Findings on urinalysis suggested pyelonephritis. Total protein was $6.0 \mathrm{~g}$ with albumin 50.8 percent, alpha-I 2.6 percent, alpha-II 11.9 percent, beta 15.4 percent and gamma globulin 19.0 percent. Apart from evidence of sinus tachycardia and digitalis effect, the electrocardiogram was normal. Chest X-ray film (Fig. 1) showed pulmonary congestion and enlargement of the left atrium and right ventricle.

Cardiac catheterization was performed after initial improvement (Table I). Atrial fibrillation developed immediately after the right atrial pressure was recorded and persisted for the remainder of the procedure. The mean left atrioventricular gradient was 20 $\mathrm{mm} \mathrm{Hg}$. With the patient in the left anterior oblique position, 30 cc of 75 percent Hypaque ${ }^{\circledR a s}$ injected

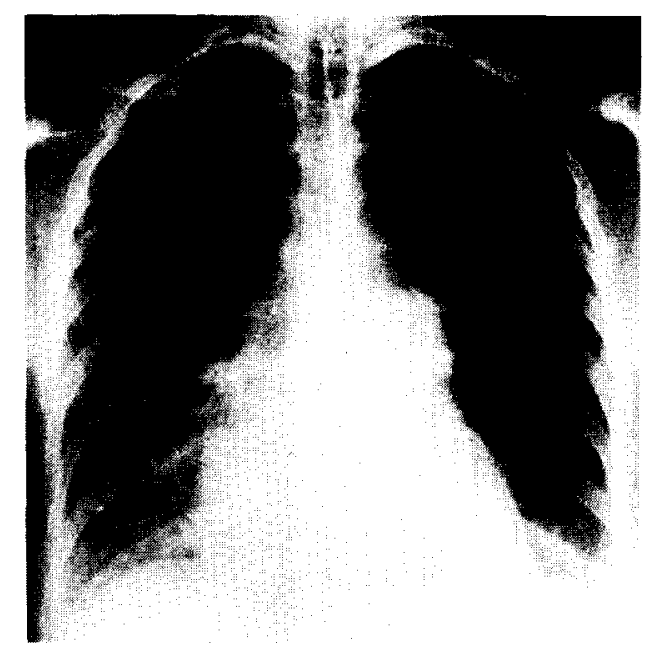

Figure 1. Anteroposterior chest X-ray film taken during first admission and before resection of the original left atrial tumor.

into the left ventricle. A large filling defect was seen in the left ventricle in diastole (Fig. 2A) moving to the left atrium in systole (Fig. 2B). There was minimal mitral regurgitation around the filling defect, thus differentiating it from a mobile stenotic mitral valve. With the patient in the right anterior oblique position, 40 cc of 75 percent Hypaque ${ }^{\circledR}$ was injected into the enlarged common pulmonary artery. The left atrium was visualized, and the filling defect was noted to elongate as it protruded through the mitral annulus during diastole.

At operation the left atrium was slightly enlarged, and there was a mass palpable from without. The left atrium was three-quarters filled by a brownish friable mass of jelly-like consistency, which was attached by a broad tumor stalk to the atrial septum in the region of the foramen ovale. The tumor and the stalk were excised with a cuff of the atrial septum, and the resultant atrial septal defect was repaired.

The tumor was 3.5 by $7 \mathrm{~cm}$, and its external surface was formed by numerous small nodules. On sectioning, it had a myxomatous appearance with numerous hemorrhagic areas. The microscopic findings were those of a
Figure 2. Single frames from a $35 \mathrm{~mm}$ cineangiocardiogram taken in the left anterior oblique position. A, the filling defect is shown occupying a large portion of the left ventricular cavity during diastole. $B$, the filling defect has returned to the left atrium during systole.

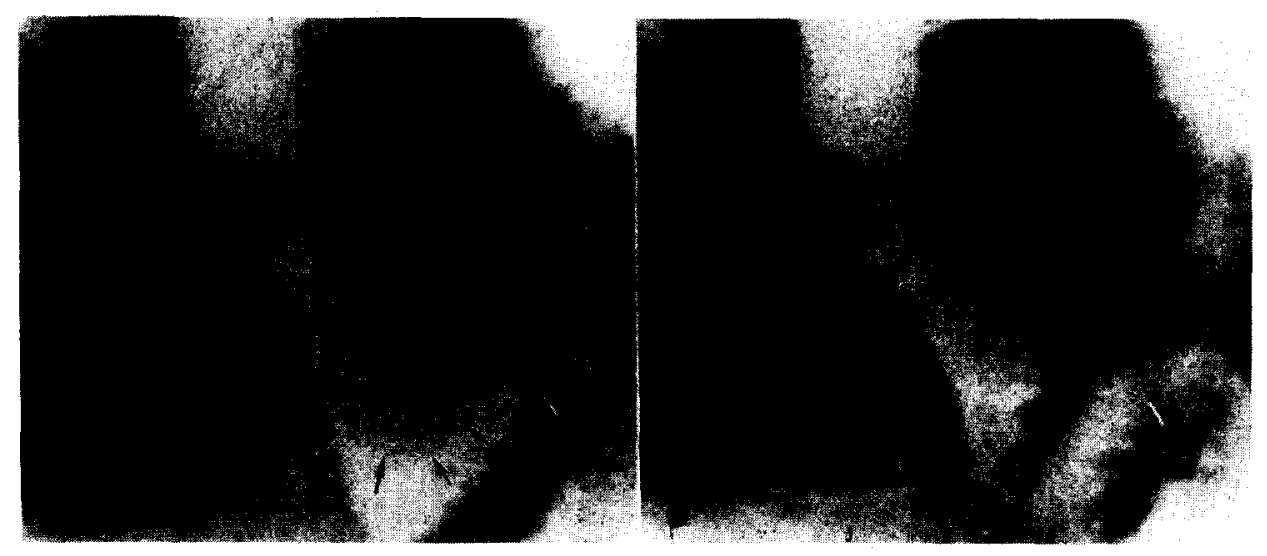



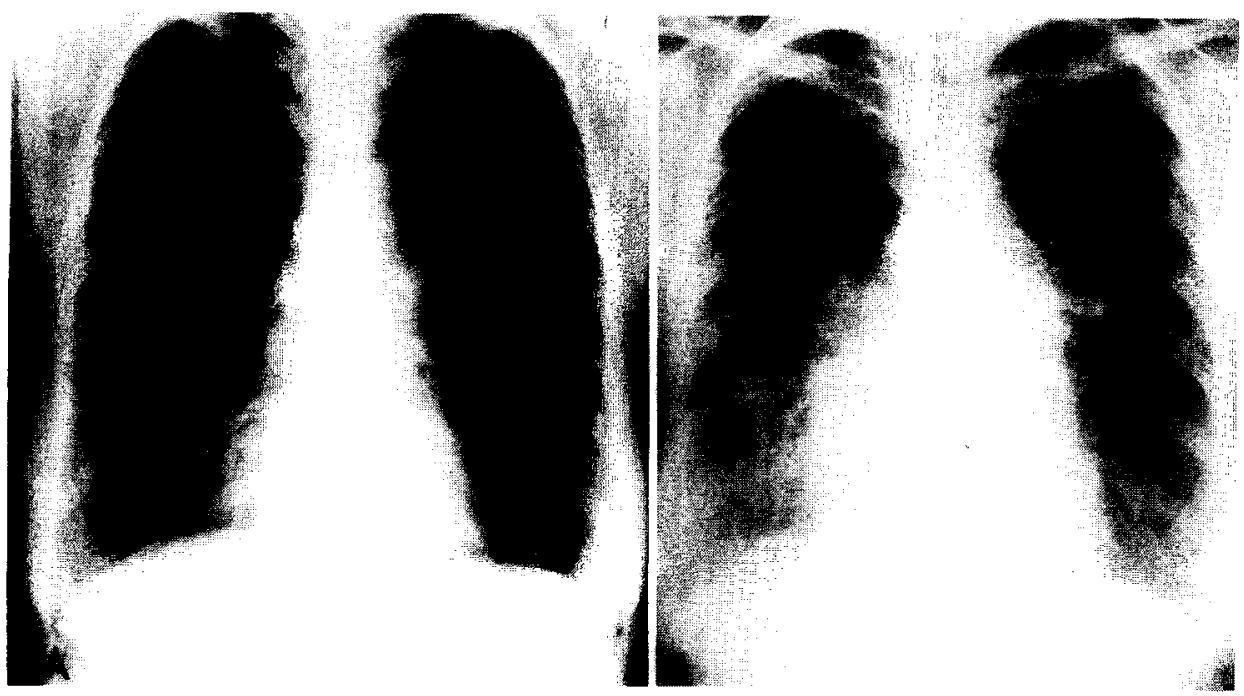

Figure 3. Anteroposterior chest $X$-ray films. A, taken 2 months after resection of the original tumor. Note the decrease in heart size and less prominent vascular markings. B, taken during the sec. ond admission, before resection of the recurrent left atrial tumor. myxomatous tumor covered with endothelium. There was no evidence of malignancy. Four sections showed that the tumor did not extend beyond the subendocardial layer into the deeper atrial muscle.

The postoperative course was uneventful, and the patient was discharged from the hospital on February 27 . 1966. Two months later, she was asymptomatic, the heart was not enlarged, and there was no left parasternal lift. The X-ray film showed a decrease in heart size with normal pulmonary vascularity (Fig. 3A). In August 1966, after an episode described as "inability to get enough air in," the cardiac examination was normal. On October 12, 1966 she complained of mild dyspnea on exertion and pedal edema.

\section{University Hospital Admission 2}

The second admission was on Necember 12, 1966. The "smothering episodes" had recurred with increasing frequency and duration.

On physical examination, the pulse was $120 / \mathrm{min}$ with a bigeminal rhythm, the blood pressure $84 / 50 \mathrm{~mm}$ $\mathrm{Hg}$ and respirations were $26 / \mathrm{min}$. The patient was pale, cyanotic and dyspneic. Giant $A$ and $V$ waves were seen in the distended neck veins with the patient sitting upright. There were fine rales at the lung bases. A left parasternal lift was prominent. The pulmonary component of the second sound was louder than the aortic. There was a grade $2 / 6$, high pitched, holosystolic murmur. No diastolic extra sounds were heard; however, a soft, mid-diastolic rumbling murmur could be heard at the apex with the patient in the left lateral position.

The electrocardiogram showed sinus tachycardia, frequent ventricular premature beats, and $\mathrm{T}$ wave changes due to digitalis. On X-ray examination (Fig. $3 B$ ) the heart was slightly enlarged with right ventricular and left atrial prominence, and there was evidence of pulmonary arterial and venous hypertension and of bilateral small pleural effusion.

At emergency right heart catheterization (Table $\mathrm{I}$ ), a cineangiocardiogram was completed by injection of 75 percent Hypaque ${ }^{\sqrt{8}}, 40 \mathrm{cc}$, into the right atrium with the patient in the right anterior oblique position.
There was no filling defect in the right atrium. The right ventricle and pulmonary artery were enlarged. A filling defect was seen in the left atrium, obstructing the mitral valve'orifice.

The patient was taken to the operating room in critical condition, and the blood pressure decreased markedly during the induction of anesthesia. She was given extracorporeal circulatory support, and the left atrium was opened. The recurrent tumor was attached to the atrial septum in the region of the fossa ovalis, and at its base old suture material was found. The myxoma was excised with a cuff of atrial wall, and the resultant atrial septal defect was repaired. There was massive bleeding from lysed adhesions, and she did not survive the procedure.

The recurrent tumor was 7.5 by $3 \mathrm{~cm}$, reddish brown in color, and had a lobulated surface (Fig. 4). The tumor stalk was attached to the left side of the atrial septum. There was extension through the foramen ovale with a small tumor component on the right side (Fig. 5). The cut surface showed numerous areas of hemorrhage. The histologic appearance was one of myxomatous tissue covered with endothelium.

At necropsy the mitral and aortic valves were normal; there was an old $1 \mathrm{~cm}$ intramural posterolateral myocardial infarction. The coronary arteries were patent and free of occlusive disease or emboli. There was considerable suture material in the region of the foramen ovale but no evidence of residual tumor in the atrial septum or of thrombi in the left atrium or left ventricle. No myxomatous emboli were found in the pulmonary or systemic circulation.

\section{Discussion}

\section{Recurrence of the Tumor}

There are several possible explanations for the recurrence of a left atrial myxoma. The first is incomplete excision of the tumor. Regrowth of a tumor occurred after simple excision of its stalk with electrocautery, and its successful removal 4 years later required excision of a portion of the atrial 
septum. ${ }^{4}$ In our patient the original tumor was excised with a portion of the atrial septum. The microscopic sections demonstrated that the tumor did not infiltrate beyond the subendocardial layer and did not extend beyond the margin of excision. Hence, inadequate excision was an unlikely cause of the recurrence.

A second explanation may be that only one of multiple tumors was excised. This event has not been reported, but multiple tumors with separate attachments have been observed frequently in the past. The atrial septum was carefully explored when the original tumor was excised, and when the recurrent tumor was excised 22 months later, old suture material was found at the base of the tumor stalk-evidence that this was a recurrent tumor and not a separate one present at the time of the initial operation.

A third explanation is growth through the foramen ovale of a right atrial myxoma to produce a "dumb-bell" or bilateral atrial myxoma.,8 The recurrent tumor in our patient was attached to the atrial septum with a broad stalk, indicating its left atrial origin. An insignificant right atrial component was present (Fig. 5).

A fourth explanation is growth from "pre-tumor" cells in the atrial septum. Whether they arise from remnants of myxoid tissue or from endothelial elements, as reported previously, ${ }^{10}$ myxomas are generally attached to the region of the fossa ovalis. Recurrent tumors should more commonly appear in the region of the fossa ovalis, as was true in our patient. This seems the most likely basis for recurrence of this left atrial myxoma.

\section{Growth of Tumor}

After onset of symptoms the clinical coursc of a patient with left atrial myxoma is more rapidly progressive than that of mitral stenosis, and this fact is helpful in the differential diagnosis. The recurrence of this myxoma permits some observations about the rate of growth of atrial myxomas, to which little attention has been given in the past.

The practical point is the time required for these tumors to reach the size needed to produce symptoms. Frequent reports of small left atrial myxomas found at necropsy suggest that these lesions often stop growing before they are large enough to produce symptoms. The report of a right atrial myxoma which produced symptoms of intermittent congestive heart failure for 43 years illustrates that these tumors may grow slowly. ${ }^{11}$ Several problems arise in attempting to determine rate of growth: (1) parts of the tumor may embolize, (2) organized thrombi may be present in addition to the tumor, (3) the location of the tumor (small tumors in critical locations may cause symptoms sooner than large ones), and (4) the

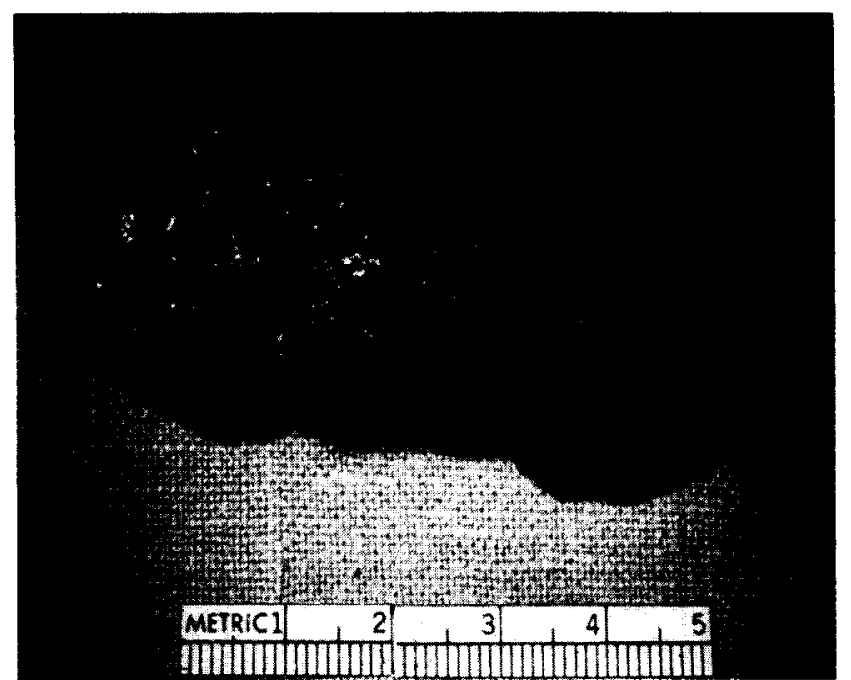

Figure 4. Gross specimen of the recurrent left atrial myxoma. Note the lobulated surface and the jelly-like consistency of the tumor.

usual inability to state the time at which the tumor originated. The report of a patient who had mitral valve surgery followed in 4 years by left ventricular inflow tract obstruction due to a 6 by 7 by $3.5 \mathrm{~cm}$ tumor suggests that growth may be fairly rapid. ${ }^{9}$

In our patient the initial tumor was excised in February 1965, and symptoms due to the recurrent tumor began in August 1966. In less than 17 months the tumor had grown enough to obstruct left ventricular inflow and in 22 months had enlarged to 7.5 by $3 \mathrm{~cm}$. These findings suggest that atrial myxomas, benign in histologic appearance, may grow quite rapidly and, because of this characteristic, may be very "malignant"-indeed rapidly fatal-lesions.

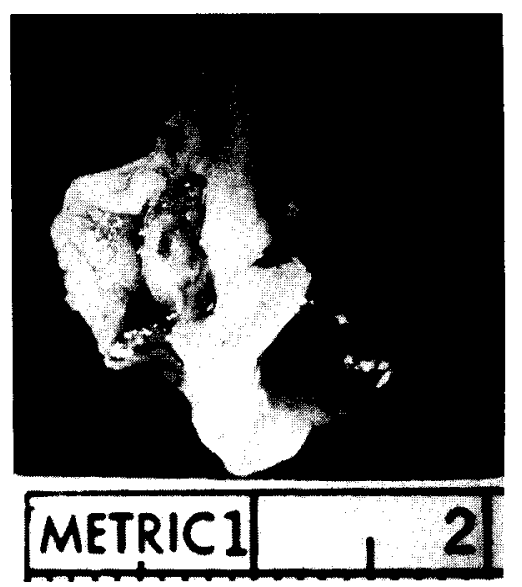

Figure 5. A portion of the atrial septum showing the smaller right atrial component of the tumor (to the reader's right), which resulted from growth of the tumor through the foramen ovale. 


\section{References}

1. Crafoord C: Discussion on late results of mitral commissurotomy. In, Henry Ford Hospital International Syrnposium on Cardiovascular Surgery: Studies in Physiology, Diagnosis and Techniques (Lam CR ed). Philadelphia, WB Saunders, 1955, p 202-203

2. Bigelow WG, Dolan FG, Campbell FW: The effect of hypothermia upon the risk of surgery. In, Seizieme Congress de la Societe Internationale de Chirugie, Copen hague, 24-31 Juillet 1955. Brussels, Imprimerie Medicale et Scientifique, p 631-644

3. Firor WB, Aldridge HE, Bigelow WG: A follow-up study of three patients after removal of left atrial myxoma five to ten years previously. J Thorac Cardiovasc Surg 51: $515-520,1966$

4. Gerbode F, Kerth WJ, Hill JD: Surgical management of tumors of the heart. Surgery 61:94-101, 1967

5. Bahl OP, Oliver GC, Ferguson TB, et al: Recurrent left atrial myxoma: report of a case. Circulation 40:673-676.
1969

6. Greenwood WF: Profile of atrial myxoma. Amer J Cardiol $21: 367-375,1968$

7. Frankenfeld RH, Waters $\mathbf{C H}$, Steiner RC: Bilateral myxomas of the heart. Ann Intern Med 53:827-838, 1960

8. Cumming GR, Finkel K: Intracardiac myxoma involving right and left atria in a young patient. J Pediat 58:559567,1961

9. Deshmukh M, Nichols HT, Goldberg H: Myxoma of the left atrium simulating restenosis of the mitral valve. Amer Heart J 58:623-629, 1959

10. Prichard RW: Tumors of the heart: review of the subject and report of one hundred and fifty cases. Arch Path (Chicago) 51:98-128, 1951

11. Strouse S: Primary benign tumor of the heart of fortythree years' duration. Arch Intern Med (Chicago) 62: $401-412,1938$ 